\title{
Serologieal Relation Between Calf Diarrhea Coronavirus and Hemagglutinating Encephalomyelitis Virus
}

\section{Brief Report}

\author{
By

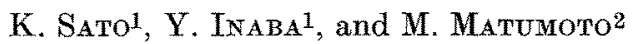 \\ 1 National Institute of Animal Health, \\ Tsukuba, Ibaraki, Japan \\ 2 Kitasato Institute, \\ Minato-ku, Tokyo, Japan \\ Accepted May 7, 1980
}

\begin{abstract}
Summary
Neutralizing (NT) and hemagglutination-inhibiting (HI) antibodies to calf diarrhea coronavirus (CDCV) and hemagglutinating encephalomyelitis virus of swine (HEV) (strain $67 \mathrm{~N}$ ) were detected in high proportions of normal adult cattle and pigs in Japan. Since comparison of NT and HI titers in the serum samples suggested an antigenic difference between the viruses, cross NT and HI tests of these viruses were carried out with antisera raised in rabbits. The homologous NT titers were markedly higher than the heterologous titers. In HI tests essentially the same results were obtained. These findings indicate the presence of a marked difference in antigenic make-up between CDCV and HEV. NT and HI tests can clearly differentiate the viruses, although there is some cross reaction.
\end{abstract}

Coronaviruses have been reported to be divided into two serological groups by the aid of the fluorescent antibody technique (4). Calf diarrhea coronavirus (CDCV) and hemagglutinating encephalomyelitis virus (HEV) $67 \mathrm{~N}$ of swine were classified in one group, together with mouse hepatitis virus type 3 and human coronavirus OC43. The other group comprized feline infectious peritonitis virus, transmissible gastroenteritis virus of swine, canine coronavirus and human coronavirus $229 \mathrm{E}$. Viruses in each group were antigenically related to each other to varying degrees, but were antigenically unrelated to coronaviruses of the second group.

During the studies on CDCV and HEV we happened to test some normal bovine and swine sera for neutralizing (NT) and hemagglutination-inhibiting (HI) antibodies to these viruses and obtained data suggestive of a marked antigenic difference between the viruses. Accordingly we conducted a direct comparison between the viruses by NT and HI tests using antisera raised in rabbits. 
CDCV passaged in bovine embryonic kidney cells (2) was kindly supplied by Dr. C. A. Mebus, University of Nebraska, U.S.A. In our laboratory the virus was shown to readily replicate and induce cytopathic effect in cultures of a continuous cell line, BEK-1, derived from bovine embryonic kidney, thus providing a sensitive, practical assay method and a satisfactory source of the virus (1). In the present study virus grown in BEK-1 cells was used. Strain $67 \mathrm{~N}$ of $\mathrm{HEV}$ (3) was kindly supplied by Dr. K. Hirai, Gifu University, Japan, and was grown in primary swine kidney cultures.

NT tests were carried out by the serum dilution method using tube cultures of BEK-1 cells with CDCV and those of primary swine kidney with HEV. Virusserum mixtures were incubated at $37^{\circ} \mathrm{C}$ for 1 hour before inoculation into 2 tube cultures per serum dilution. The virus dose per tube was 100 TCID $_{50}$. The antibody titer was expressed as the reciprocal of the highest serum dilution which showed neutralization in at least one of the 2 tubes. An antibody titer of 2 or higher was taken as positive.

HI tests were carried out by the microtiter method $(5,6)$. Infectious culture fluid was used as HA antigen. For HI tests the serum was inactivated at $56^{\circ} \mathrm{C}$ for 30 minutes and treated with Kaolin to remove non-specific inhibitors and with packed chicken erythrocytes to remove antibodies to the erythrocytes. The antigenserum mixtures were incubated at room temperature for 1 hour, mixed with chicken erythrocyte suspension and incubated at room temperature for 1 hour. The HI antibody titer was expressed as the reciprocal of the highest serum dilution showing complete $\mathrm{HI}$ and titers of 2 or higher were taken as positive.

Serum samples from 10 normal adult cattle and 59 pigs were tested for NT and HI antibodies to CDCV and HEV. Many of the bovine and porcine serum samples contained NT and HI antibodies to these viruses, indicating dissemination of the viruses or antigenically related viruses in these animals. Furthermore, the bovine sera had markedly higher NT titers to CDCV than $H E V$, while the porcine sera showed similar NT titers against both viruses; NT titer ratio, HEV/CDCV, ranged from 1:64 to $1: 4096$ with bovine sera and from $1: 1 / 4$ to $1: 16$ with porcine sera. Representative results are shown in Table 1 . HI titers of bovine sera were

Table 1. Neutralizing (NT) and hemagglutination-inhibiting (HI) antibodies against calt diarrhea coronavitus (CDOV) and hemagglatinating encephalomyelitis virus (HEV) in representative bovine and swine sera

\begin{tabular}{|c|c|c|c|c|c|}
\hline \multirow[b]{2}{*}{ Animal } & \multirow{2}{*}{$\begin{array}{l}\text { Serum } \\
\text { No. }\end{array}$} & \multicolumn{2}{|c|}{ NT titer with } & \multicolumn{2}{|c|}{ HI titer with } \\
\hline & & CDCV & $\mathrm{HEV}$ & $\mathrm{CDCV}$ & $\mathrm{HEV}$ \\
\hline \multirow{5}{*}{ Cattle } & 1 & 32,768 & 32 & 640 & 40 \\
\hline & 2 & 512 & 8 & 80 & 10 \\
\hline & 3 & 32,768 & 8 & 160 & 20 \\
\hline & 4 & 32,768 & 32 & 1,280 & 80 \\
\hline & 5 & 2,048 & 8 & 320 & 20 \\
\hline \multirow{5}{*}{ Swine } & 1 & 512 & 2,048 & 20 & 40 \\
\hline & 2 & 512 & 512 & 20 & 40 \\
\hline & 3 & 512 & 32 & 10 & 40 \\
\hline & 4 & 128 & 128 & 10 & 40 \\
\hline & 5 & 128 & 128 & 40 & 40 \\
\hline
\end{tabular}


also higher to CDCV than HEV, although they were low; HI titer ratio, HEV/ CDCV, ranged from $1: 2$ to $1: 16$. HI titers of porcine sera were very low to both viruses. HI titers of representative sera are also shown in Table 1. These results suggested that there are antigenic differences between these two viruses.

Therefore, we conducted a direct comparison between CDCV and HEV by cross NT and HI tests. The antisera used were prepared in specific pathogen free rabbits with virus grown in cultured cells and concentrated by ultracentrifugation (1). The animals received an intravenous dose of the virus suspension, followed at 3 and 6 weeks intervals, by two intramuscular doses of the virus suspension mixed with Freund's complete adjuvant, and sera were obtained 3 weeks after the last dose. The results are summarized in Table 2 . The homologous NT titers were much higher than the heterologous titers. In HI tests similar results were also obtained. All the serum samples obtained before the immunization were invariably negative in these tests.

These findings show the presence of a marked difference in the antigenic makeup between these two viruses. NT and HI tests can clearly differentiate the viruses, although there is some cross reaction.

Table 2. Cross neutralization (NT) and hemagglutination-inhibition (HI) tests with hemagglutinating encephalomyelitis virus ( $\mathrm{HEV}$ ) and calf diarrhea coronavirus (CDCV)

\begin{tabular}{lrrrrr}
\hline & \multicolumn{2}{c}{ NT titer with } & & \multicolumn{2}{c}{ HI titer with } \\
\cline { 2 - 3 } \cline { 5 - 6 } Antiserum & HEV & CDCV & & HEV & CDCV \\
\hline HEV & & & & \\
No. 1 & 65,536 & 64 & & 320 & 40 \\
No. 2 & $\geq 65,536$ & 512 & & 1,280 & 160 \\
\hline CDCV & & & & 10 & 160 \\
No. 3 & 4 & 2,048 & 1,024 & 10 & 80 \\
No. 4 & & &
\end{tabular}

\section{References}

1. Inaba, Y., Sato, K., Kurogt, H., Takahash, E., Ito, Y., Omori, T., Goto, Y., Matumoto, M. : Replication of bovine coronavirus in cell line BEK-1 culture. Arch. Virol. 50, 339-342 (1976).

2. Mebus, C. A., Staik, E. L., Refodes, M. B., Twiehaus, M. J. : Neonatal calf diarrhea: propagation, attenuation and characteristics of a coronavirus-like agent. Amer. J. vet. Res. 34, 145-150(1973).

3. Mengeling, W. L., Boothe, A. D., Rrrchie, A. E. : Characteristies of a coronavirus (strain 67N) of pigs. Amer. J. vet. Res. 33, 297-308 (1972).

4. Pedersen, N. C., Ward, J., Mengeling, W. L. : Antigenic relationship of the feline infectious peritonitis virus to coronaviruses of other species. Arch. Virol. 58, 45-53 (1978).

5. Pensaert, M. B., Callebaut, P. E.: Characteristics of a coronavirus causing vomition and wasting in pigs. Arch. ges. Virusforseh. 44, 35-50 (1974).

6. Sato, K., Inaba, Y., Kurogi, H., Tatrahashr, E., Satona, K., Omoni, T., Matuмото, M.: Hemagglutination by calf diarrhea coronavirus. Vet. Microbiol. 2, 83-87 (1977).

Authors' address: Dr. K. SAto, National Institute of Animal Health, Tsulsuba, Ibaraki, Japan. 